\title{
A percepção ambiental do corpo docente de uma escola pública rural em Manaus (Amazonas)
}

\author{
Joanne Régis Costa ${ }^{1}$ \\ José Edison Carvalho Soares ${ }^{2}$ \\ Sandra Tápia-Coral ${ }^{3}$ \\ Adelaide Moraes da Mota ${ }^{4}$
}

\begin{abstract}
RESUMO: O presente trabalho foi desenvolvido em uma escola localizada em área rural de Manaus (AM), a fim de conhecer a percepção dos professores sobre meio ambiente. Foram aplicados formulários com perguntas abertas, respondidos por $83 \%$ do grupo docente. Os resultados revelaram que a visão naturalista e a antropocêntrica são predominantes. A temática ambiental é restrita, geralmente, à sala de aula. Com isso, verificou-se ser imprescindível que a escola avance para ações extra-curriculares, aumentando o elo com o cotidiano dos alunos, de formar a ampliar a visão de mundo destes e a tornar efetiva a educação ambiental na referida escola.
\end{abstract}

Palavras-chave: educação ambiental; escola; meio ambiente.

\section{INTRODUÇÃO}

A Educação Ambiental (EA) pode ser uma ferramenta na mudança de mentalidades e de atitudes na relação homem-ambiente. No âmbito escolar, a EA possibilita a realização de um trabalho de intervenção sistemático, planejado e controlado (PELICIONI, 2002).

Segundo Marques (1993), um trabalho de Educação Ambiental será mais rico se tiver como base um levantamento das formas de percepção do ambiente. Sendo assim, é importante conhecer a visão que o outro tem tanto do seu lugar como do espaço antes de se realizar qualquer trabalho que aborde a EA.

Projetos de pesquisa que abordem as relações do ser humano com o meio ambiente devem necessariamente incluir estudos de percepção como parte integrante da abordagem interdisciplinar (FIORI, 2002).

Por definição, percepção é o ato, o efeito ou a faculdade de perceber, adquirir conhecimento a partir de algo por meio dos sentidos, compreender e ouvir. A percepção ambiental abrange a compreensão das inter-relações entre o meio ambiente e os indivíduos, ou seja, como a sociedade percebe o seu meio circundante, expressando suas opiniões, expectativas e propondo linhas de condutas (AMANTE, 2001).

objetivo deste trabalho foi compreender a percepção sobre meio ambiente de professores de uma escola localizada em meio rural, em plena Amazônia Central, a fim de realizar um trabalho de EA com bases locais, partindo da realidade do público-alvo.

\footnotetext{
$1 \quad$ Pesquisadora da Embrapa Amazônia Ambiental, atua com pesquisa participativa, sistemas agroflorestais educação ambiental e comunicação ambiental em pequenas comunidades rurais.

$2 \quad$ Instituto Federal de Educação, Ciência e Tecnologia do Estado do Amazonas.

3 Instituto Nacional de Pesquisas da Amazônia.

4 Instituto Nacional de Pesquisas da Amazônia.
} 


\section{METODOLOGIA}

A referida pesquisa foi aplicada na Escola Municipal Profa. Neuza dos Santos Ribeiro, localizada na comunidade Pau Rosa, assentamento Tarumã-Mirim, nas coordenadas geográficas latitude 60002'18.3"S e longitude 20047'43.7'W, zona rural de Manaus. O acesso à localidade é feito pela Rodovia BR-174 (Manaus - Boa Vista/RR) à altura do km 21, no ramal do Pau Rosa. O Projeto de Assentamento Tarumã-Mirim (Manaus-AM) foi criado em 1992 pelo Instituto Nacional de Colonização e Reforma Agrária (Incra), com uma extensão de 42.910,76 ha e capacidade para 1.042 lotes com tamanho médio de 25 ha destinados à agricultura familiar e 7.088,62 ha de reservas florestais (INCRA, 1999).

A Escola oferece $01^{\circ}$ e $2^{\circ}$ períodos, o Ensino Fundamental ( $1^{\circ}$ ao $9^{\circ}$ ano), o Programa de Aceleração da Aprendizagem e o Ensino de Jovens e Adultos (EJA). Ao todo, são 12 professores e 200 alunos matriculados, nos turnos da manhã e da tarde. A estrutura física é composta por: oito salas de aula, um laboratório de informática (desativado), quatro banheiros, uma cantina e uma área para apresentações culturais. A biblioteca está em fase de estruturação e não está aberta ao público.

A obtenção dos dados foi feita mediante formulários, aplicados aos 10 professores, o que representa $83 \%$ do total de docentes. O questionário foi composto por perguntas abertas e também foi aplicado ao gestor da escola.

Para a análise das concepções sobre o meio ambiente, recorreu-se às categorias delimitadas por Reigota (1999): naturalista, antropocêntrica e globalizante. Os professores cuja representação de meio ambiente é antropocêntrica desenvolvem uma prática pedagógica centrada na transmissão de conteúdos científicos, que evidenciam a utilidade dos recursos naturais para sobrevivência do ser humano. A visão globalizante alterna a transmissão de conteúdos com atividades inovadoras, enfatizando aspectos não-imediatos do meio ambiente. Já a representação naturalista evidencia somente os aspectos naturais, identificam o meio ambiente com a natureza e assim a sua prática pedagógica está voltada para o conhecimento dessa natureza, preservada ou deteriorada (REIGOTA, 1999).

\section{RESULTADOS E DISCUSSÃO}

Os professores são procedentes da zona urbana de Manaus (AM), na qual concluíram sua formação acadêmica. Tanto a gestora como a coordenadora pedagógica consideram importante a inserção da Educação Ambiental (EA) nas suas práticas pedagógicas. A escola procura trabalhar a questão ambiental, principalmente, em datas comemorativas, como Semana de Meio Ambiente e Dia da Árvore, oportunidades em que são convidados técnicos para ministrarem palestras sobre o assunto.

Todos os entrevistados afirmaram que abordam a questão ambiental em suas aulas, ou seja, discute-se a temática em todas as disciplinas. Segundo os professores, faz-se um elo entre a teoria específica de sua disciplina com os temas relacionados à conservação e à preservação do meio ambiente. Isso está em concordância com os Parâmetros Curriculares Nacionais (PCNs) que mencionam a Educação Ambiental como um tema transversal que deve ser estudado em todas as séries e em todas as disciplinas, independente da ciência. Cada disciplina, dentro da sua especificidade, pode contribuir para que o estudante amplie sua visão sobre o assunto, para que construa o conhecimento sobre meio ambiente e expressem suas opiniões, sensações e pensamentos.

Os temas abordados em sala de aula são: desenvolvimento sustentável, agricultura, poluição, qualidade da água, reflorestamento, higiene pessoal, o homem e o meio ambiente, animais ameaçados de extinção, queimadas, extração ilegal de madeira, tráfico de animais, importância da preservação da floresta, entre outros. Verificou-se que os educadores procuram trabalhar a sensibilização dos educandos quanto aos problemas ambientais. Porém, apesar de considerarem o tema importante, as discussões ficam restritas à sala de aula. 
Somente uma professora desenvolve atividades fora da sala de aula, a horta escolar, que funciona como um laboratório vivo, com atividades semanais envolvendo os alunos de todas as turmas. Também se realiza coleta de lixo no espaço escolar, porém é efetuada de forma não seletiva.

De uma forma geral, isso demonstra que a questão ambiental fica restrita ao campo teórico. Cabe à escola oferecer situações nas quais os alunos possam pôr em prática sua capacidade crítica, promover atividades que possibilitem uma participação concreta dos alunos, desde a definição dos objetivos, metas, metodologias para desenvolver a capacidade de intervenção na própria realidade.

Nas proximidades da referida escola, existe um rio preservado e extensas áreas de florestas primárias e secundárias, campinas, propriedades agrícolas com impactos ambientais negativos e positivos e agricultores com uma rica história a ser transmitida, isto é, um leque de opções onde poderiam ser feitas atividades com os alunos.

Nesse cenário, o ensino poderia ser organizado de forma a proporcionar oportunidades para o debate em sala de aula, mas também ações práticas desenvolvidas fora dela, conforme afirma Berna (2004, p.30):

\begin{abstract}
"O educador ambiental deve procurar colocar os alunos em situações que sejam formadoras, como por exemplo, diante de uma agressão ambiental ou conservação ambiental, apresentando os meios de compreensão do meio ambiente. Em termos ambientais isso não constitui dificuldade, uma vez que o meio ambiente está em toda a nossa volta. Dissociada dessa realidade, a educação ambiental não teria razão de ser. Entretanto, mais importante que dominar informações sobre um rio ou ecossistema da região é usar o meio ambiente local como motivador."
\end{abstract}

Os problemas ambientais próximos dos alunos podem ser melhor compreendidos com a observação in loco e a partir do entendimento das relações que ocorrem nas cadeias alimentares reais. Martins (2003) questiona porque não fazer da escola um espaço socialmente construído nas relações cotidianas, que são permeadas por atividades econômicas, sociais e políticas.

Diante desse quadro, percebe-se que as representações dos professores se identificam com as categorias naturalista e antropocêntrica, havendo uma maior predominância da visão naturalista. Para Reigota (1999), a concepção naturalista retrata o ambiente como sendo sinônimo de natureza intocada, o que se aproxima da vertente ecológica presente nos livros didáticos, onde modelos tradicionais ainda persistem. Isso denota que reflexões relacionadas à realidade científica sobre meio ambiente estão sendo ainda negligenciadas naquela escola.

A visão naturalista separa o ser humano do meio ambiente, colocando-o como mero observador, sem laços de pertencimento e responsabilidade. Neste caso, a natureza é apreciada pela beleza cênica, demonstrando certa dose de religiosidade e romantismo e deve ser preservada por ser provedora de recursos sobre os quais temos o direito de uso. Essas representações parecem indicar distorções de caráter epistemológica na leitura do mundo (GUERRA; TAGLIEBER, 2002) e são coerentes com uma concepção fragmentada de aprendizagem.

A visão antropocêntrica também é fragmentada, segundo Martins (2003) e precisa ser substituída por uma visão holística, sistêmica, interdisciplinar e próxima.

Esses resultados decorrem da formação acadêmica dos professores. Segundo Sato (1997), os modelos tradicionais de Educação ainda persistem e são negligenciadas as explicações das relações humanas com o ambiente. 
Frazão et al. (2010) e Bezerra e Gonçalves (2007) obtiveram resultados semelhantes, com o predomínio da visão naturalista, em pesquisa com professores em outros estados brasileiros.

$\mathrm{Na}$ escola pesquisada, inserida na Amazônia Central, pode-se afirmar que apenas um professor tem a visão globalizante, a qual valoriza o meio ambiente, procura trabalhar a questão ambiental dentro e fora da sala de aula, alternando a transmissão de conteúdos com atividades inovadoras, no caso da horta escolar, enfatizando aspectos não imediatos do meio ambiente. Segundo Reigota (1995), essa visão engloba aspectos naturais, políticos, sociais, econômicos, filosóficos e culturais. O ser humano é compreendido como ser social que vive em comunidade. Contudo, o professor age sozinho neste caso e, dessa forma, as ações ficam limitadas.

As principais dificuldades para desenvolver ações na área ambiental no âmbito escolar segundo os professores são: falta de material didático e de conhecimentos e estratégias de abordagem e a falta de interesse dos alunos. Trinta por cento dos entrevistados afirmaram que os alunos são passivos e desinteressados. Trabalhar com eles, portanto, é considerado algo difícil.

Percebe-se que a escola tem dificuldades em trabalhar o tema com maior profundidade. A escola seria apenas um local de reprodução e não de geração de conhecimentos, de cidadãos questionadores de sua própria realidade, o que contribui para a intensificação das desigualdades sociais, ao invés de ser um lugar de formação de cidadãos capazes de lutar por transformação social e ambiental.

\section{CONCLUSÕES}

Houve o predomínio das visões naturalista e antropocêntrica na percepção ambiental dos docentes. Os professores afirmam abordar a questão ambiental em suas disciplinas, porém, as situações de aprendizagem relacionadas a esse tema são mantidas no modelo tradicional de educação. A maioria apenas reproduz o ensino fragmentado e desvinculado da realidade próxima ao estudante.

A próxima etapa do trabalho será ampliar o diagnóstico para os discentes e, posteriormente, propor ações conjuntas capazes de mudar a realidade atual.

Os resultados obtidos apontam para a necessidade de desenvolver a visão globalizante, com vistas a trabalhar não só com conceitos, mas ações práticas, reflexivas e críticas, as quais ampliem a visão de mundo dos estudantes e apontem para mudanças, visando uma melhor qualidade de vida no Assentamento Tarumã-Mirim.

\section{REFERÊNCIAS}

AMANTE, F. A. Carta de enchente da Praça da Bandeira e Tijuca. 2001. 110 f. Trabalho de Conclusão de Curso (Monografia) - Faculdade de Geografia, Universidade Estadual do Rio de Janeiro, Rio de Janeiro, 2001.

BERNA, V. Como fazer educação ambiental. 2. ed. São Paulo: Paulus, 2004.

BEZERRA, T. M. O.; GONÇALVES, A. A. C. Concepções de meio ambiente e educação ambiental por professores da Escola Agrotécnica Federal de Vitória de Santo Antão, PE. Revista Biotemas, Santa Catarina, v. 20, n. 3, p. 115-125, 2007.

FIORI, A di. Ambiente e educação: abordagens metodológicas da percepção ambiental voltadas a uma Unidade de Conservação. 111 f. 2002. Dissertação (Mestrado em Ecologia e Recursos Naturais) - Programa de Pós-Graduação em Ecologia e Recursos Naturais, Universidade Federal de São Carlos, São Paulo, 2002. 
FRAZÃO, J. O.; SILVA, J. M.; CASTRO, C. S. S. de. Percepção ambiental de alunos e professores na preservação das tartarugas marinhas na Praia da Pipa - RN. Rev. eletrônica Mestr. Educ. Ambient., Rio Grande, v. 24, jan./jul. 2010.

GUERRA, A. F. S.; TAGLIEBER, J. E. A inserção da educação ambiental no currículo: o olhar dos pesquisadores de um programa de mestrado em educação. GE: Educação Ambiental, Itajaí, n. 22, 2002.

INCRA-AM. Informações do Projeto de Assentamento Tarumã-Mirim. Manaus, 1999. $67 p$.

MARQUES, J. G. W. Etnoecologia, educação ambiental e superação da pobreza em áreas de manguezais. In: ENCONTRO NACIONAL DE EDUCAÇÃO AMBIENTAL EM ÁREAS DE MANGUEZAIS, 1, 1993, Maragogipe. Anais... Maragogipe: UFBA, 1993, p. 29-35.

MARTINS, M. T. J. Escola, meio ambiente e relações: reprodução ou mudança? 2003. 59 f. Trabalho de Conclusão de Curso (Monografia) - Faculdade de Educação, Universidade do Estado do Rio de Janeiro, Rio de Janeiro, 2003.

PELICIONI, A. F. Educação Ambiental na escola: uma experiência de sucesso. Disponível em: < www.neoambiental.com.br>. Acesso em: 24 ago. 2010.

REIGOTA, M. Ecologia, elites e intelligentsia na América Latina: um estudo de suas representações sociais. São Paulo: Annablume, 1999.

Meio ambiente e representação social. São Paulo: Cortez, 1995.

SATO, Michele. Educação Para o Ambiente Amazônico. 246 f, 1997. Tese (Doutorado em Ciências) - Programa de Pós-Graduação em Ecologia e Recursos Naturais. Universidade Federal de São Carlos-SP, 1997. 